\title{
JOURNAL
}

of Health Inequalities

\section{Non-melanoma skin cancer as an occupational disease. What is the impact on the society and the welfare system?}

\author{
Charis Girvalaki ${ }^{1,2}$, Antonella Cardone1, Patricia Weinert ${ }^{3}$, Swen M. John ${ }^{3,4}$ \\ 'European Cancer Patient Coalition, Brussels, Belgium \\ ${ }^{2}$ Faculty of Medicine, University of Crete, Heraklion, Greece \\ ${ }^{3}$ Institute for Interdisciplinary Dermatological Prevention and Rehabilitation, University of Osnabrück, Germany \\ ${ }^{4}$ Department of Dermatology, Environmental Medicine, Health Theory, University of Osnabrück, Germany
}

\begin{abstract}
The aim of this special article is to highlight the relevance of NMSC as an occupational disease as well as the regulatory gaps at European and Member State level, while at the same time promoting early screening and raising awareness.

To support that, we conducted an extensive search (PubMed, Google Scholar) of the most recent scientific work related to NMSC and its epidemiology worldwide and in Europe, the causality of the disease, the economic burden of work-related UVR skin cancer, the role of screening and early detection and the regulatory gaps.

Non-melanoma skin cancer (NMSC) refers to all the types of cancer of the skin that are not melanoma. In recent decades, the incidence of NMSC has continuously increased and will continue to do so in Europe and worldwide. NMSC is by far the most common cancer diagnosed in light-skinned people. The role of ultraviolet radiation (UVR) in carcinogenesis has been investigated by scientists and solar radiation has been classified by WHO/IARC as a Group 1 human carcinogen. Indeed, 90\% of NMSC can be attributed to excessive exposure to UVR. Outdoor workers are exposed to an UVR dose of at least 2 to 3 times higher than indoor workers. NMSC has a significant impact in reducing patients' quality of life as they potentially undergo repeated rounds of surgery or recurrence and, as a result, can suffer significant consequences for their appearance, self-esteem, and well-being. For these reasons, actions and measures are required at European level in order to promote early screening and detection of skin malignancies as well as to increase awareness and protection of outdoor workers.
\end{abstract}

KEY WORDS: non-melanoma skin cancer, occupational disease, ultraviolet radiation, sun exposure.

ADDRESS FOR CORRESPONDENCE: Charis Girvalaki, Clinic of Social and Family Medicine, Faculty of Medicine, University of Crete, Heraklion, Crete, Greece, European Cancer Patient Coalition, Brussels, Belgium, e-mail: charis.girvalaki@ecpc.org

\section{INTRODUCTION}

Non-melanoma skin cancer (NMSC) refers to all the types of cancer of the skin that are not melanoma. The vast majority (95\%) of NMSC cases are basal cell carcinoma (BCC) and cutaneous squamous cell carcinoma (CSCC) while both types of NMSC can be diagnosed by visual inspection by a dermatologist [1].

Exposure to ultraviolet radiation (UVR) is considered to be the main risk factor for the development of skin can- cer [2]. The pivotal role of UVR in carcinogenesis has been investigated by scientists, in such level that solar radiation has been declared as a Group 1 human carcinogen by the International Agency for Research on Cancer (IARC) [3]. A systematic review has found that outdoor workers have increased risk of developing squamous cell carcinoma (SCC) and actinic keratosis (that is to say, intraepidermal SCC) by $77 \%$, and for BCC by $43 \%$ respectively, compared with the general population $[4,5]$. More recent European 
studies reveal that the risk for long-time outdoor work for CSCC and BCC is doubled compared to average population [6-8]. Considering that Europe has more than 14.5 million active workers that spend at least $75 \%$ of their working time outdoors, special attention should be paid to this kind of occupational exposure [9].

The World Health Organization (WHO) and the International Labour Organization (ILO) prioritized this topic, including the more specific impact of occupational exposure to UVR, and they are currently developing a methodology to assess the global disease burden of work-related skin cancer by solar UVR [10].

In addition, the nine co-hosting organizations of the Multi-Stakeholder Summit on Occupational Skin Cancer in 2019, representing patient advocacy groups, trade unions, occupational safety and health professionals, social security representatives, dermatologists and oncologists, called for the implementation of a systematic approach to address the Non-Melanoma Skin Cancer Epidemic [11]

\section{EPIDEMIOLOGY}

In recent decades, the incidence of NMSC has continuously increased and will continue to do so, in Europe $(+43.9 \%$ until 2040$)$ and worldwide (+90.2\% until 2040) (Figs. 1 and 2) [12].

According to the World Health Organization (WHO), between 2 and 3 million NMSC cases are recorded in the world every year [13], while white populations are more susceptible to develop this type of malignancy [14]. Australia (147.5/100.000), New Zealand (138.4/100.000), USA (55.4/100.00), Canada (48.5/100.000), Switzerland (44.4/100.000), Ireland (43.4/100.000), The Nether-

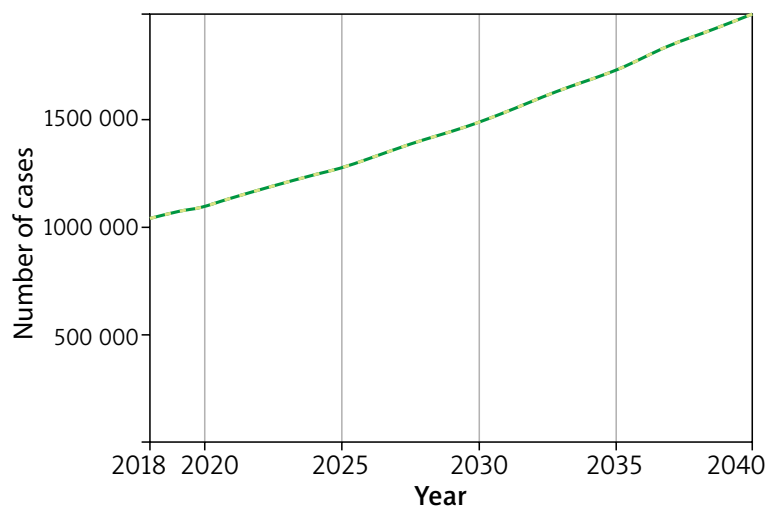

\begin{tabular}{ccc}
\hline World & \multicolumn{2}{c}{ Demographic change } \\
\cline { 2 - 3 } & 2018 & 2040 \\
\cline { 2 - 3 } & 1042045 & $1990921(+90.2 \%)$ \\
\hline
\end{tabular}

Graph production: Global Cancer Observatory (http://gco.iarc.fr/)@ International Agency for Research on Cancer 2018

FIG. 1. Estimated number of incident cases of non-melanoma skin cancer, from 2018 to 2040 worldwide (both sexes, all ages) [9] lands (31.3/100.000), Germany (27.5/100.000), Luxembourg (23.9/100.000), Belgium (23.3/100.000), United Kingdom (22.8/100.000) and France (21.1/100.000) rank among the countries with the highest estimated age-standardized incidence rates of NMSC in 2018, both sexes, all ages (Fig. 3) [12].

\section{OCCUPATIONAL EXPOSURE}

Occupational exposure to solar radiation is an important factor and it is usually measured by exposure type, i.e. whether it is recreational or occupational, or by job type, i.e. whether it is indoor or outdoor exposure. Until recently, not much data existed that clearly defines the difference between the nature of the UVR exposure (occupational or leisure), or that provides sufficient evidence on the root cause of the disease to support the establishment of regulations for outdoor workers. However, exposure assessments regarding those who work outdoors taken from several countries have shown that those sampled are often exposed to significantly higher levels of UVR than the general population. More specifically, the level of exposure vastly exceeds the recommended limits for eight hours working outdoors of 1.3 Standard Erythemal Doses (SED; $1 \mathrm{SED}=100 \mathrm{Jm}^{-2}$ of erythemal weighted UV irradiance, which is sufficient to cause sunburn in fair skinned individuals of Fitzpatrick Skin type 1: Highly sensitive, always burns, never tans) [15].

Additional data from the European Agency for Safety and Health at Work (EU-OSHA) showed that UVR is a carcinogen, which has been identified in 36 different employment sectors within the European Union and that about 14.5 million people who work outdoors are exposed for at least $75 \%$ of their working hours. The

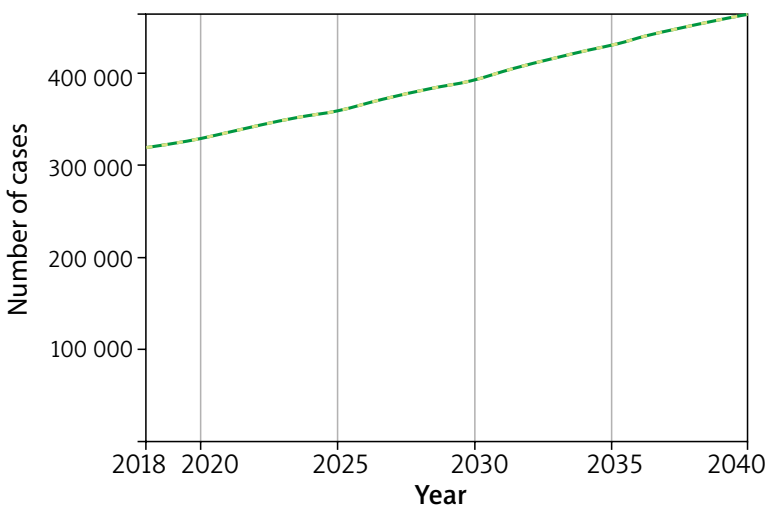

\begin{tabular}{ccc}
\hline Europe & \multicolumn{2}{c}{ Demographic change } \\
\cline { 2 - 3 } & 2018 & 2040 \\
\cline { 2 - 3 } & 318345 & $463014(+43.9 \%)$ \\
\hline
\end{tabular}

Graph production: Global Cancer Observatory (http://gco.iarcfr/)@ International Agency for Research on Cancer 2018

FIG. 2. Estimated number of incident cases of non-melanoma skin cancer, from 2018 to 2040 Europe (both sexes, all ages) [9] 


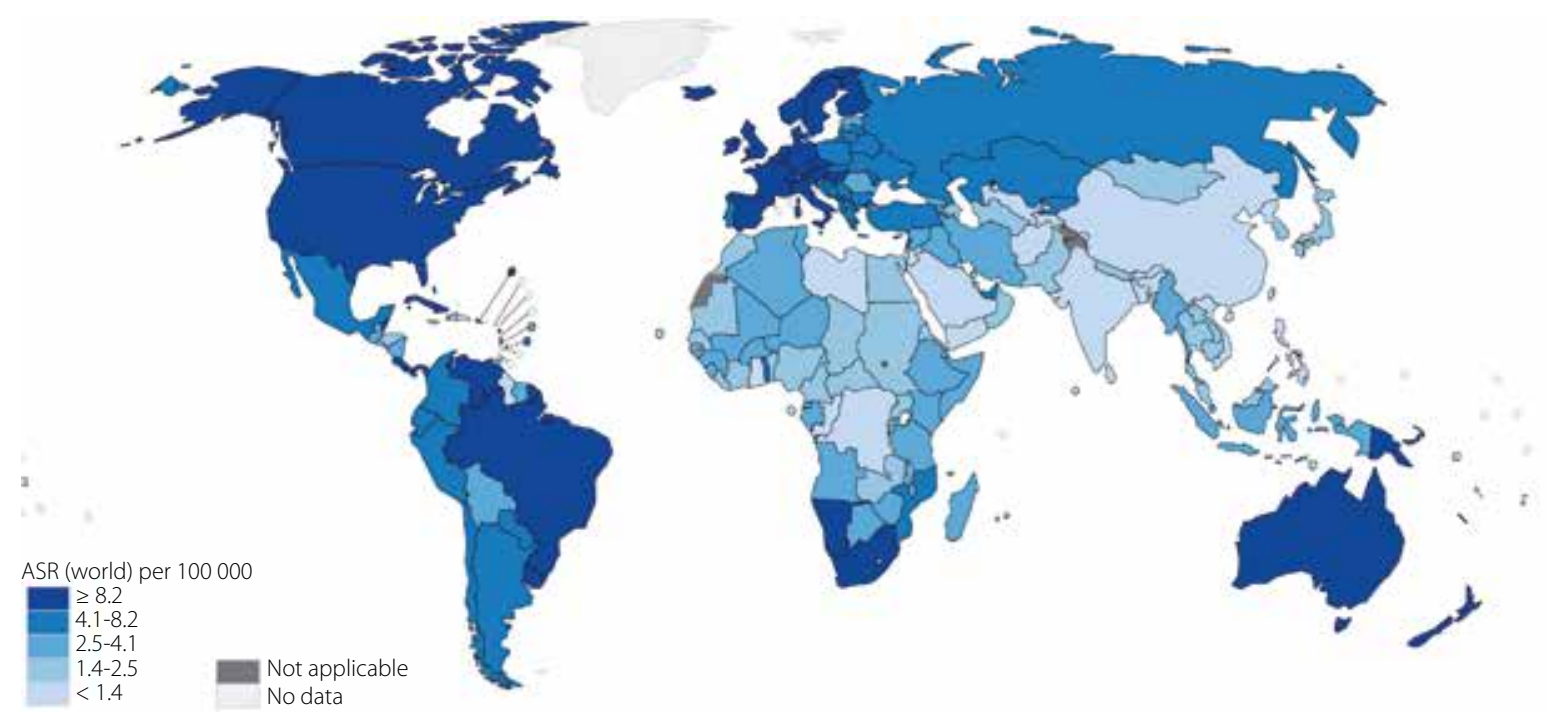

Graph production: Global Cancer Observatory (http://gco.iarc.fr/)@ International Agency for Research on Cancer 2018

FIG. 3. Estimated age-standardized incidence rates (world) in 2018, non-melanoma skin cancer, both sexes, all ages [9]

workers exposed most to UV radiation are in the agriculture, hunting and construction sectors. Some of the occupations included in this data are farmers, silviculturists/horticulturists, farm workers, commercial garden and park workers, postmen and sorters, newspaper delivery workers, physical education instructors, trainers, coaches and childcare workers [9].

A recent study from thirteen workplaces in the provinces of British Columbia, Ontario, and Nova Scotia, Canada found that exposure for outdoor workers was 6.1 SED/day [16], accordingly measurements conducted in Australian construction workers [17] and road workers from New Zealand [18] and Spain [19] showed very high daily solar UVR exposure (9.9, 5 and $6.11 \mathrm{SED} /$ day respectively). US data from lifeguards (1.7 SED to 6.2 SED/day) [20], outdoor occupations from France [21], gardeners [22] and workers [23] from Denmark (receiving a median 224 SED per year and a semi-annual exposure of 361.8 SED respectively), also confirmed high exposures. A German study comprising 1,000 outdoor workers from 97 different occupations also showed that exposures of up to $5 \mathrm{SED} /$ day are common [24]. An additional study, performed with the same state-ofthe-art UVR dosimeters in outdoor workers from the construction sector in Romania, with a duration of 7 months and comprising two different geographic locations, found a daily exposure ranging from 1.28 SED to 6.4 SED [25].

All the above findings highlight the alarming exposure of outdoor workers to UVR and the need for the national and European health authorities to take preventive action given that the International Commission on Non-Ionizing Radiation Protection (ICNIRP) guidelines suggested limit value of up to 1.33 SED daily is vastly exceeded [15].

However, skin cancer from occupational exposure to UVR is not widely recognized as an occupational disease. Furthermore, there remains only a limited number of studies on cutaneous malignancies occurring from occupational exposure. A review from 2010 supports the link between occupational UV exposure and SCC while at the same time pointing out an unclear link with BCC due to significant methodological limitations in the published studies [26]. A more recent meta-analysis by Bauer et al., which included 23 scientific articles with sufficient data, found that outdoor workers are at significantly increased risk for BCC $(p=0.014)$ [4]. Additionally, a large multicentre European case-control study, which compared the risk of developing BCC, SCC, melanoma and actinic keratosis (AK) between 1416 outdoor and 1863 indoor workers found that outdoor workers were at a significantly increased risk of developing AK, SCC and BCC over the indoor workers included in the study, with additional strong trends observed in the case of melanoma. Increased number of years of outdoor work (i.e. five or more) were associated with a threefold risk of all types of skin cancer and AK [27]. In addition, a cohort study based on the Cancer Registry of Norway, which included 24,917 men also supported claims that UVR exposure is a significant factor in the elevated risk of skin cancer (Cutaneous melanoma-CM and NMSC) observed in North Sea offshore workers [28]. Further evidence comes from a recent Italian study which found that fishermen, sailors, and lifeguards (Odds Ratio (OR): 4.3; 95\% Confidence Interval $(\mathrm{Cl}): 1.1-16.4)$, foundry and metallurgy workers (OR: 5.58; 95\% CI: 1.14-27.3), and mechanics, fixers, and welders (OR: 8.2; 95\% CI: 1.76-37.9) are at 
an increased risk for developing NMSC [29]. A final example, the EPIDERM study in United Kingdom (UK) from 1996 to 2012, revealed that sun/sunlight/ultraviolet light was the cause in $99 \%$ of the reported cases of work-related skin neoplasia [30]. A recent large German case control study showed a twofold risk for SCC and BCC in highly exposed outdoor workers compared to the average population $[6,7]$. Loney et al. 2020, recently provided a comparative overview on the existing global data on the association of outdoor work and BCC and CSCC, respectively [8]

\section{THE FINANCIAL BURDEN}

The economic burden of skin cancer due to UVR has continuously put national governments and their healthcare systems under significant economic strain. In Europe, the annual direct costs for the treatment of patients with advanced melanoma, is estimated to a range from $€ 2,916$ in Italy all the way up to $€ 22,671$ in Sweden, which remains three times higher than the next highest costs which are to be found in $(€ 7,005)$ and the UK $(€ 6,887)$ [31]. In addition, mortality costs in England are six times greater than those in Sweden (€20,408 vs $€ 3,511$ respectively), while morbidity costs vary between $€ 103$ in Sweden and $€ 4550$ in England. These costs in England are found to be seven times over costs in Denmark (€658) and forty times over the costs in Sweden $(€ 103)$ [31].

Data from the Danish Ministry of the Interior and Health also showed that the direct yearly costs of malignant melanoma and NMSC were more than $€ 30$ million in the 3 years after diagnosis, corresponding to $0.2 \%$ of the total Danish health budget (€14.3 billion), [32] and approximately to $5 \%$ of the hospital budget for cancer patients [33].

For Canada, on the other hand, the direct and indirect costs of occupational NMSC cases are CAN \$28.9 million (\$15.9 million for BCC and \$13.0 million for SCC) while for intangible costs are $\$ 5.7$ million ( $\$ 0.6$ million for BCC and \$5.1 million for SCC) [34]. Cases of NMSC in Australia comprise $75 \%$ of all cancers and account for AUD $\$ 511$ million in 2010 [35], making NMSC the most costly cancer type which places an increasing burden on the country's healthcare sector, while in the US, the estimated total annual cost for NMSC care amounts to $\$ 650$ million [36].

Reduction of quality of life is also an important issue to consider for NMSC patients as they potentially undergo repeated rounds of surgery and, as a result, can suffer significant consequences for their appearance, self-esteem, and well-being. In fact, the impact of NMSC on a patient's life derive from the cancer itself, from the way that the doctor will choose to intervene and from what follows the intervention. Many NMSCs appear on the face or other visible part of the body [37] and many may be symptomatic causing bleeding, pain, pruritus, functional and cosmetic concerns [38]. In addition, the vast majority of the NMSC cases are treated with surgery and this has an important effect in patients' daily life routine and financial status which is disrupted while repeated treatments or recurrences may prolong this situation. Generally, NMSC on the bases of long-term sun damage are characterized by a high chronicity, and not rarely the need for continuous medical attention for the rest of the patient's life. Further, in many cases treatment results on cosmetic and functional abnormalities from scarring which can further affect the psychology of the patients and the course of the treatment and healing [38].

Several studies in the past tried to depict the most important factors of NMSC, in terms of the quality of life for the patient. Some of the most frequently identified are physical deformity, cosmetic concerns, and psychosocial function $[39,40]$. Consequently, costs for NMSC are estimated to be even higher, approximately, $€ 1,040$ to $€ 2,040$ million per year in Europe [34]. In addition, it has also been shown that BCC and SCC patients experience similar levels of anxiety and depression following diagnosis and treatment [41]. All the above, demonstrate the importance of prevention with regards to NMSC.

\section{PREVENTION MEASURES}

Prevention measures such as primary prevention, early detection, treatment and regular follow-up, targeting outdoor workers could reduce the costs and be beneficial from a health economic perspective $[42,43]$ and also increased quality-of-life, functional ability and overall health [42].

Health surveillance and regular skin cancer screening are pivotal for early detection. Apart from the regular inspection of the skin from a dermatologist or another healthcare professional, raising awareness by providing outdoor workers with information about the risks and available assistance is also important. However, scientific data shows that outdoor workers with higher UVR exposure are less likely to have received a skin examination from health care providers than the average (indoor) worker $[44,45]$.

Increasing investment on screening and early detection is indeed a reciprocating strategy, a strategy that pays off both sides, the health system and the patient outcomes. Results from a population based study (SCREEN) conducted in Germany showed that introducing widespread skin cancer screening in Germany resulted in savings potential calculated at over $€ 575$ million annually $[6,7]$, and more specifically, the inspection of the body by a healthcare professional resulted in earlier diagnosis of melanoma, BCC and SCC [42].

Following the recommendations of the International Commission on Non-Ionizing Radiation Protection, UVR exposure can be reduced for outdoor workers also by taking sun-protective measures, such as adjusting outdoor working hours or seeking shade whenever possible and using shading structures for lunch and other breaks. In additions, appropriate use of personal sun-protective 
measures such as wearing hats, protective sunglasses, long-sleeved shirts and trousers, and applying sunscreen to the remaining skin areas are necessary to protect the outdoor workers from UVR exposure [15].

\section{POLICY AND LEGISLATION}

Despite the solid evidence that outdoor workers in various workplaces across Europe are exposed to highly elevated levels of UVR and are consequently at a significantly increased risk of developing NMSC, this evidence has yet not been translated into a common European regulatory approach towards standards for UVR prevention on work sites in the form of management protocols for work-related skin cancer and/or a common European agreement regarding financial compensation for patients with a work-related skin cancer history [5].

In addition, only a few countries cover compensation for occupational NMSC. In detail:

- in Australia, legislation for NMSC as an occupational disease comes from state legislation [46],

- in Canada, it is organized by provinces and territories [46],

- in Europe, only seven countries (Germany-DE, France-FR, Czech Republic-CZ, Denmark-DK, Romania-RO, Italy-IT and Portugal-PT) recognize cutaneous squamous cell carcinoma in outdoor workers as an occupational disease while basal cell carcinoma (6 EU countries: DE, FR, DK, RO, IT and PT), actinic keratosis ( $5 \mathrm{EU}$ countries: DE, FR, DK, RO and IT), Bowen's disease (5 EU countries: DE, FR, CZ, DK and $\mathrm{RO}$ ) and malignant melanoma ( $3 \mathrm{EU}$ countries: DK, RO, PT) are not regularly approved as potentially work-induced diseases. Finally, only three countries (FR, DE, DK) which participated in the StanDerm survey established a national programme for the prevention, management or compensation of occupational skin cancers acquired due to work-related UVR exposure [46].

In 2017, the European Parliament, the Council and the Commission committed themselves to the European Pillar of Social Rights, which consists of 20 key principles for more effective rights for citizens. Principle 10, in particular, states that: "a) Workers have the right to a high level of protection of their health and safety at work. b) Workers have the right to a working environment adapted to their professional needs and which enables them to prolong their participation in the labour market", setting the ground for the introduction of targeted measures for outdoor workers exposed to UVR protection [47].

Scientific work from across the EU and worldwide provides solid evidence to put prevention of UVR exposure for outdoor workers as priority and highlights the importance and necessity for new policies and legislation adaption.

The White paper [48] for the improved protection of outdoor workers from solar ultraviolet radiation, also provides recommendations for policymakers, doctors, employers, workers and patient advocacy groups on five fields of action to address the unmet needs of NMSC patients, which are:

- Policymakers should improve the legislative framework to protect outdoor workers more effectively and build accessibility for regular screenings of this high risk group of workers and thus earlier treatments. In the European Union, NMSC should be officially recognized as an occupational disease within the next legislative period.

- Healthcare professionals and policy makers should work together to ensure a common European registration for NMSC in cancer registries.

- Employers should find appropriate ways to monitor UVR exposure and implement cost-effective techniques for protective behaviours and skin cancer screenings for outdoor workers.

- Health professionals should improve reporting of occupational NMSC.

- Patient advocacy groups, doctors and other health professionals as well as employers should collaborate to promote skin cancer prevention and protective working practices and to address the unmet needs of retired outdoor workers with chronic persisting NMSC [48].

Additional evidence shows that unregistered employment in many sectors with an elevated level of UV radiation exposure (agriculture, hunting and construction) [9] is something that European policy makers and legislative authorities should take into account. Recent data shows that although 1 to 25 of the EU28 workforce is in the agriculture, forestry and fishing sector., $15 \%$ of the agricultural workforce and $32 \%$ of all employees in the agricultural sector have no formal employment contract [49], while in the construction sector the unregistered employment is $19 \%$ [50]. As such, the population at risk is much larger than the official records or trade unions report. European and national organizations should consider measurements that will work synergistically in order for prevention measures to have a meaningful impact to the real extent of the working population with elevated exposure to UVR and consequently to increased NMSC risk.

The latest WHO World Cancer Report also highlights the need for protective measures against hazardous exposure to sunlight [51]. Finally, Europe's Beating Cancer Plan, calls for: "further legislative and soft measures to reduce exposure to carcinogenic substances in the workplace, in products and in the environment, and to UV and ionising radiations from natural and artificial sources" [52].

\section{CONCLUSIONS}

Outdoor workers in various workplaces across the world are exposed to intense UVR, which results in the high incidence of NMSC. For patients, NMSC is a poten- 
tially life-threatening, highly chronic and recalcitrant disease, which, inter alia, has a huge impact on their quality of life and it thus affecting their social life and mental health stability.

However, NMSC is not yet recognized as an occupational disease at pan European level and there is no effective legislation to protect outdoor workers.

This paper is a call for action to increase awareness among and protection for those who work outdoors and to establish the necessary preventive methods such as regular screening for early detection and treatment, and to increase the use of protective methods currently at disposal including protective clothing and sunscreens in order to prevent further NMSC incidences.

\section{DISCLOSURE}

The authors report no conflict of interest.

\section{References}

1. Gillard M, Wang TS, Johnson TM. Nonmelanoma cutaneous malignancies. In: Oncology. An Evidence-Based Approach. Chang AE, Ganz PA, Hayes DF, et al. (eds.). Springer, New York 2006: 1102-1118.

2. Armstrong BK, Kricker A. The epidemiology of UV induced skin cancer. J Photochem Photobiol B 2001; 63 (1-3): 8-18.

3. Dayan AD. Solar and ultraviolet radiation. IARC monographs on the evaluation of carcinogenic risks to humans. Vol 55 J Clin Pathol 1993; 46 (9): 880.

4. Bauer A, Diepgen TL, Schmitt J. Is occupational solar ultraviolet irradiation a relevant risk factor for basal cell carcinoma? A systematic review and meta-analysis of the epidemiological literature. Br J Dermatol 2011; 165 (3): 612-625.

5. Schmitt J, Seidler A, Diepgen TL, Bauer A. Occupational ultraviolet light exposure increases the risk for the development of cutaneous squamous cell carcinoma: a systematic review and meta-analysis. Br J Dermatol 2011; 164 (2): 291-307.

6. Schmitt J, Haufe E, Trautmann F, et al. Occupational UV-exposure is a major risk factor for basal cell carcinoma: Results of the population-based case-control study FB-181. J Occup Environ Med 2018; 60 (1): 36-43.

7. Schmitt J, Haufe E, Trautmann F, et al. Is UV-exposure acquired at work the most important risk factor for cutaneous squamous cell carcinoma? Results of the population-based case-control study FB-181. Br J Dermatol 2018; 178 (2): 462-472.

8. Loney T, Paulo MS, Modenese A, et al. Global evidence on occupational sun exposure and keratinocyte cancers: a systematic review. Br J Dermatol 2020; doi: 10.1111/bjd.19152.

9. European Agency for Safety and Health at Work. New and Emerging Risks in Occupational Safety and Health. European Risk Observatory. Office for Official Publications of the European Communities, Luxembourg 2009. Available from: https:// osha.europa.eu/en/publications/new-and-emerging-risks-occupational-safety-and-health/view (accessed: 15 June 2020).

10. Silva Paulo M, Adam B, Akagwu C, et al. WHO/ILO work-related burden of disease and injury: Protocol for systematic reviews of occupational exposure to solar ultraviolet radiation and of the effect of occupational exposure to solar ultraviolet radiation on melanoma and non-melanoma skin cancer. Environ Int 2019; 126: 804-815.

11. Global Call to Action to End the Non-Melanoma Skin Cancer Epidemic in Outdoor Workers. 2019. Available from: https:// eadv.org/cms-admin/showfile/NMSC\%20Call\%20to\%20 Action_Updated_June.pdf (accessed: 15 June 2020).

12. Globocan 2018. Global Cancer Observatory. Available from: http:/gco.iarc.fr (accessed: 15 June 2020).

13. World Health Organization. Skin cancers. Available from: https:// www.who.int/health-topics/ultraviolet-radiation\#tab=tab_1 (accessed: 15 June 2020).

14. Trakatelli M, Ulrich C, Del Marmol V, et al. Epidemiology of nonmelanoma skin cancer (NMSC) in Europe: accurate and comparable data are needed for effective public health monitoring and interventions. Br J Dermatol 2007;156 (Suppl 3): 1-7.

15. International Commission on Non-Ionizing Radiation Protection. ICNIRP statement-protection of workers against ultraviolet radiation. Health Phys 2010; 99 (1): 66-87.

16. Peters CE, Pasko E, Strahlendorf P, et al. Solar ultraviolet radiation exposure among outdoor workers in three Canadian provinces. Ann Work Expo Health 2019; 63 (6): 679-688.

17. Gies P, Wright J. Measured solar ultraviolet radiation exposures of outdoor workers in Queensland in the building and construction industry. Photochem Photobiol 2003; 78 (4): 342-348.

18. Hammond V, Reeder AI, Gray A. Patterns of real-time occupational ultraviolet radiation exposure among a sample of outdoor workers in New Zealand. Public Health 2009; 123 (2):182-187.

19. John SM, Trakatelli M, Gehring R, et al. Consensus report: Recognizing non-melanoma skin cancer, including actinic keratosis, as an occupational disease-A Call to Action. J Eur Acad Dermatol Venereol 2016; 30 (Suppl 3): 38-45.

20. Gies P, Glanz K, O’Riordan D, et al. Measured occupational solar UVR exposures of lifeguards in pool settings. Am J Ind Med 2009; 52 (8): 645-653.

21. Boniol M, Koechlin A, Boniol M, et al. Occupational UV exposure in French outdoor workers. J Occup Environ Med 2015; 57 (3): 315-320.

22. Thieden E, Philipsen PA, Heydenreich J, Wulf HC. UV radiation exposure related to age, sex, occupation, and sun behavior based on time-stamped personal dosimeter readings. Arch Dermatol 2004; 140 (2): 197-203.

23. Grandahl K, Eriksen P, Ibler KS, et al. Measurements of solar ultraviolet radiation exposure at work and at leisure in Danish workers. Photochem Photobiol 2018; 94 (4): 807-814.

24. DGUV Website. IFA. Technical Information Radiation. GENESIS-UV. Available from: https://www.dguv.de/ifa/fachinfos/strahlung/genesis-uv/aktuelle-ergebnisse/index-2.jsp (accessed: 15 June 2020).

25. Moldovan HR, Wittlich M, John SM, et al. Exposure to solar $\mathrm{UV}$ radiation in outdoor construction workers using personal dosimetry. Environ Res 2020; 181: 108967.

26. Schmitt J, Diepgen T, Bauer A. Occupational exposure to nonartificial UV-light and non-melanocytic skin cancer-a systematic review concerning a new occupational disease. J Dtsch Dermatol Ges 2010; 8 (4): 250-263 
27. Trakatelli M, Barkitzi K, Apap C, et al. Skin cancer risk in outdoor workers: a European multicenter case-control study. J Eur Acad Dermatol Venereol 2016; 30 (Suppl 3): 5-11.

28. Stenehjem JS, Robsahm TE, Bråtveit $M$, et al. Ultraviolet radiation and skin cancer risk in offshore workers. Occup Med (Lond) 2017; 67 (7): 569-573.

29. Larese Filon F, Buric M, Fluehler C. UV exposure, preventive habits, risk perception, and occupation in NMSC patients: A casecontrol study in Trieste (NE Italy). Photodermatol Photoimmunol Photomed 2019; 35 (1): 24-30.

30. Turner S, Forman SD, McNamee R, et al. Investigating work-related neoplasia associated with solar radiation. Occup Med (Lond) 2015; 65 (1): 22-28.

31. Krensel M, Schäfer I, Augustin M. Cost-of-illness of melanoma in Europe-a systematic review of the published literature. J Eur Acad Dermatol Venereol 2019; 33 (3): 504-510.

32. The healthcare system in a national perspective. Danish Ministry of the Interior and Health, Copenhagen 2010. Available from: https://www.copenhagenconsensus.com/sites/default/files/ConsensusReportDanishHealth_final.pdf (accessed: 15 June 2020).

33. Kalseth J, Halsteinli V, Halvorsen T, et al. Costs of cancer in the Nordic countries-A comparative study of health care costs and public income loss compensation payments related to cancer in the Nordic countries in 2007. SINTEF Technology and Society, Trondheim 2011

34. Mofidi A, Tompa E, Spencer J, et al. The economic burden of occupational non-melanoma skin cancer due to solar radiation. J Occup Environ Hyg 2018; 15 (6): 481-491.

35. Fransen M, Karahalios A, Sharma N, et al. Non-melanoma skin cancer in Australia. Med J Aust 2012; 197 (10): 565-568.

36. Mudigonda T, Pearce DJ, Yentzer BA, et al. The economic impact of non-melanoma skin cancer: a review. J Natl Compr Canc Netw 2010; 8 (8): 888-896.

37. Eisemann N, Waldmann A, Geller AC, et al. Non-melanoma skin cancer incidence and impact of skin cancer screening on incidence. J Inv Derm 2014; 134 (1): 43-50.

38. Coates E, Chee SN, Lowe PM. Dermatological challenges in solid organ transplant recipients: the first 18 months of a dedicated transplant dermatology database. Pigment Cell Melanoma Res 2013; 26 (3): E4.

39. Rhee JS, Loberiza FR, Matthews BA, et al. Quality of life assessment in nonmelanoma cervicofacial skin cancer. Laryngoscope 2003; 113 (2): 215-220.

40. Essers B, Nieman F, Prins M, et al. Perceptions of facial aesthetics in surgical patients with basal cell carcinoma. J Eur Acad Dermatol Venereol 2007; 21 (9): 1209-1214.

41. Winterbottom A, Harcourt D. Patients' experience of the diagnosis and treatment of skin cancer. J Adv Nurs 2004; 48 (3): 226-233.

42. Kornek T, Augustin M. Skin cancer prevention. J Dtsch Dermatol Ges 2013; 11 (4): 283-298.

43. Carter R, Marks R, Hill D. Could a national skin cancer primary prevention campaign in Australia be worthwhile?: an economic perspective. Health Promot Int 1999; 14 (1): 73-82.

44. Rosenman KD, Gardiner J, Swanson GM, et al. Use of skin-cancer prevention strategies among farmers and their spouses. Am J Prev Med 1995; 11 (5): 342-347.
45. Bernardes Filho F, Alves AD, Towersey L, et al. The skin health of fishermen in Guanabara Bay, Rio de Janeiro, Brazil. Int J Dermatol 2019; 58 (4): 483-90.

46. Ulrich C, Salavastru CA, Agner T, et al. The European Status Quo in legal recognition and patient-care services of occupational skin cancer. J Eur Acad Dermatol Venereol 2016; 30 (Suppl 3): 46-51.

47. The European Pillar of Social Rights in 20 principles. Available from: https://ec.europa.eu/commission/priorities/deeper-and-fairer-economic-and-monetary-union/european-pillar-social-rights/european-pillar-social-rights-20-principles_en (accessed: 15 June 2020).

48. White paper. Improved Protection of Outdoor Workers from Solar Ultraviolet Radiation. Available from: https://www.eadv. org/cms-admin/showfile/White\%20Paper.pdf (accessed: 15 June 2020).

49. Williams CC, Horodnic A. Tackling undeclared work in the agricultural sector. European Platform Undeclared Work. Available from: https://ec.europa.eu/social/BlobServlet?docId=20424\&langId=en (accessed: 15 June 2020).

50. Cremers J, Williams CC. Tackling undeclared work in the construction industry: A learning resource. European Platform Undeclared Work. Available from: https://ec.europa.eu/social/ BlobServlet?docId=18132\&langId=en (accessed: 15 June 2020).

51. Wild C, Weiderpass E, Stewart BW. World cancer report 2020. World Health Organization, international agency for research on cancer. Available from: https://www.iarc.fr/world-cancer-report-highlights (accessed: 15 June 2020).

52. Europe's Beating Cancer Plan. Available from: https://ec.europa.eu/info/law/better-regulation/have-your-say/initiatives/12154-Europe-s-Beating-Cancer-Plan (accessed: 15 June 2020).

\section{AUTHORS' CONTRIBUTIONS}

AC, CG, PW, SMJ conceived the idea of the presented study. CG conducted the literature review. All authors discussed the results and contributed to the final manuscript. 